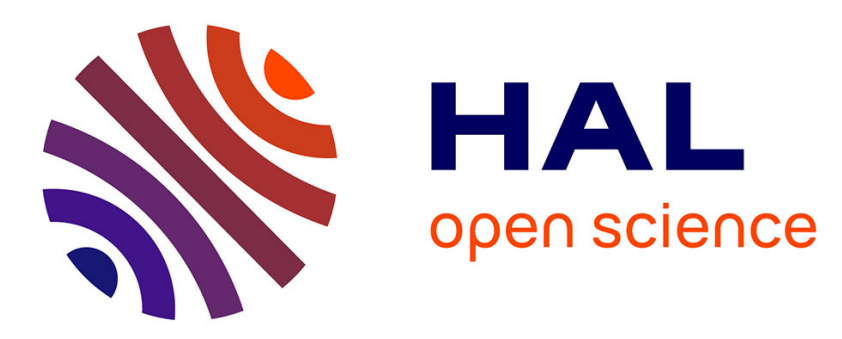

\title{
Influence of the urban block structure on the flow pattern along a flooded street
}

M.A. Mejia Morales, Sébastien Proust, Emmanuel Mignot, André Paquier

\section{To cite this version:}

M.A. Mejia Morales, Sébastien Proust, Emmanuel Mignot, André Paquier. Influence of the urban block structure on the flow pattern along a flooded street. 38th IAHR World Congress, Sep 2019, Panama City, Panama. pp.6066-6073. hal-02610031

\section{HAL Id: hal-02610031 https://hal.inrae.fr/hal-02610031}

Submitted on 16 May 2020

HAL is a multi-disciplinary open access archive for the deposit and dissemination of scientific research documents, whether they are published or not. The documents may come from teaching and research institutions in France or abroad, or from public or private research centers.
L'archive ouverte pluridisciplinaire HAL, est destinée au dépôt et à la diffusion de documents scientifiques de niveau recherche, publiés ou non, émanant des établissements d'enseignement et de recherche français ou étrangers, des laboratoires publics ou privés. 


\title{
INFLUENCE OF THE URBAN BLOCK STRUCTURE ON THE FLOW PATTERN ALONG A FLOODED STREET
}

\author{
MIGUEL ANGEL MEJIA MORALES ${ }^{(1,2)}$, SEBASTIEN PROUST ${ }^{(2)}$, EMMANUEL MIGNOT $^{(1,3)}$ \& ANDRE \\ PAQUIER ${ }^{(2)}$ \\ (1) Institut National des Sciences Appliquées de Lyon, Villeurbanne, France. \\ (2) Institut National de Recherche en Sciences et Technologies pour l'Environnement et l'Agriculture, Villeurbanne, France. \\ miguel-angel.mejia-morales@irstea.fr, sebastien.proust@irstea.fr, andre.paquier@irstea.fr \\ ${ }^{(3)}$ Laboratoire de Mécanique des Fluides et d'Acoustique - INSA de Lyon, Villeurbanne, France. \\ emmanuel.mignot@insa-lyon.fr
}

\begin{abstract}
The study of flooding in urban environments has some complexity, mainly due to the presence of buildings, among others (e.g., vehicles, street furniture, drainage system, underground transportation system). These buildings and their facilities are grouped into blocks that are normally assumed to be impervious in urban flood studies. However, water enters these blocks through different openings such as e.g., windows, doors, gates, fences, and these lateral flow exchanges between streets and blocks can locally alter the flow pattern. In order to study these exchange processes and their influence on both flow depth and velocity in the streets during flood events, experiments were conducted on a devoted physical model termed MURI (Urban Model for the study of Inundation Risk), at Irstea, Lyon-Villeurbanne, France. The present study focused on two geometric configurations, a straight street flanked by two lateral cavities, and a straight street flanked by one-side opening. These flows were also compared to a quasi-uniform flow (reference flow without openings). The experiments have shown that a detailed description of the building blocks is required if flow depths and velocities (flood hazard) has to be locally estimated.
\end{abstract}

Keywords: physical model, urban flood, laboratory experiment, lateral flow exchanges

\section{INTRODUCTION}

Urban flooding is among the most prevalent disasters worldwide lately according to Wahlstrom et al. (2015), and to minimize the flood risk it is necessary to improve flood hazard predictions. The damages caused by these events are particularly significant in urban settlements, and given the growing number of people living in these areas worldwide (United Nations, 2015), studying the impact of urban flooding more exhaustively is a particularly relevant issue.

The study of urban flooding requires the incorporation of various details in order to faithfully reproduce the full complexity of flows. Nowadays, there are several studies and research works on urban flood processes, mainly using $1 \mathrm{D}$ or/and $2 \mathrm{D}$ numerical models, and to a lesser extent, using physical laboratory models. Nevertheless, numerical models need to be validated by reliable reference data, which are often not available, because of the short duration of these events, as well as the danger that their immediate observation entails.

In this case, laboratory models are a convenient way to investigate flood flows patterns in complex geometries, providing reliable information under controlled conditions (Finaud-Guyot et al., 2018, Mignot et al., 2018).

The vast majority of existing studies based on laboratory models consider buildings or urban blocks as impervious structures. There are studies that represent them as aligned and staggered impervious square obstacles (Testa et al., 2007; Yoon, 2007; Soares-Frazão et al., 2008; Huang et al., 2014; Tomiczek et al., 2016). Others studies represent a pattern of impervious blocks or buildings with geometries closer to reality (Ishigaki et al. 2003; Smith et al., 2016). However, a few studies consider these structures as pervious buildings (Zhou et al., 2016; Sturm et al., 2018).

The purpose of this work is to assess the impact of the lateral flow exchanges between streets and building blocks on flow depth and velocity patterns in a flooded street. For this, two configurations are considered herein: (i) a straight street flanked by two lateral cavities, which may represent a pair of rectangular blocks adjacent to the street that are closed along three facades, representing e.g. parking lots or gardens, and (ii) a straight street flanked by a one-side opening, representing e.g. pedestrian crossing through a urban block.

\section{EXPERIMENTAL SET-UP AND MEASUREMENTS}

The experimental model MURI is a $5.4 \mathrm{~m}$ long and $3.8 \mathrm{~m}$ wide rectangular tilting platform with 3 longitudinal streets crossing 3 transverse streets (figure 1). The bottom of the streets is made of PVC plates, and the 
sidewalls are made of transparent plastic (PETG), which represent the facades of the urban blocks of a neighborhood. Each street is supplied with water by a dedicated inlet tank, and the inflow discharge is regulated by an electromagnetic valve and monitored with a flowmeter. At the entrance of each street, a honeycomb straightens the flow. At the exit of each street, a vertical weir enables water surface profiles to be controlled. Each outlet tank is equipped with an electromagnetic flowmeter to measure the outflow discharge.

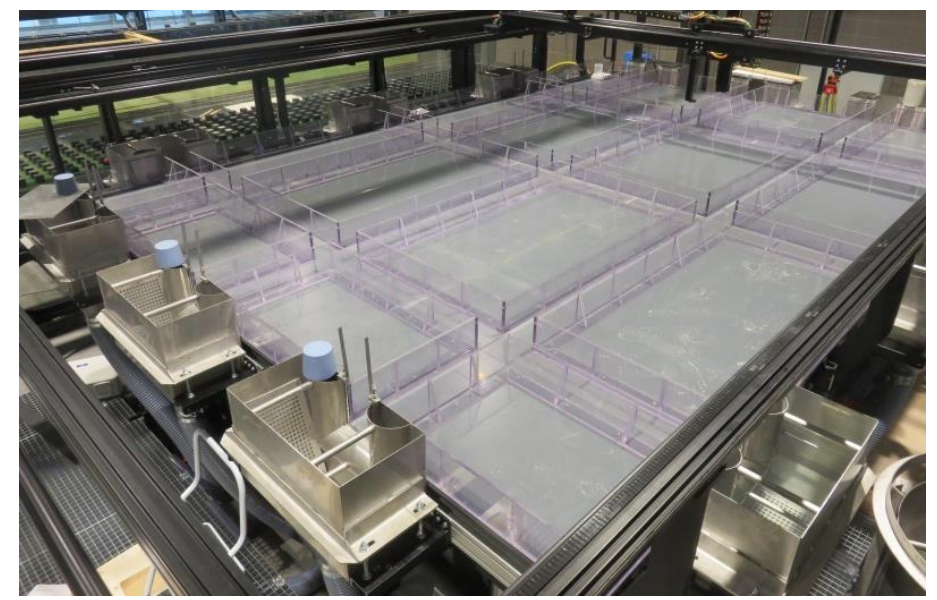

Figure 1. Urban Model for the study of Inundation Risk (MURI), with a 3 streets $\times 3$ streets configuration. Laboratory of Hydraulics and Hydro-morphology, Irstea, Villeurbanne, France.

\subsection{Straight street flanked by two lateral cavities}

The first configuration studied consists in a $3.7 \mathrm{~m}$ long and $0.15 \mathrm{~m}$ wide (width $\mathrm{b}$ ) straight street with a rectangular cross-section, which is flanked by two lateral cavities of same cross-section as the street (figure 2) but with a shorter length. It should be noted that there is no step at the connection street / cavity. The inflow discharge is $3 \mathrm{l} / \mathrm{s}$, and the longitudinal bottom slope is $0.12 \%$. The experiment is carried out under steady flow conditions and subcritical regime. To ensure the subcritical regime, the downstream weir crest height is set to $w=2 \mathrm{~cm}$.

Flow depths are measured along the street using an ultrasonic distance-measuring sensor (BAUMER UNDK 2016914/S35A) with a resolution better than $0.3 \mathrm{~mm}$, which is mounted on an automated displacement system. The three velocity components are measured using an Acoustic Doppler Velocimeter (ADV) with a sidelooking probe (NORTEK Vectrino+) of $0.5 \%$ of reading accuracy. The velocity measurements are taken along two cross-sections (transects A-B and C-D in figure 2), with 17 vertical profiles in each section. The first section is located $45 \mathrm{~cm}$ upstream of the cavities and the second one $30 \mathrm{~cm}$ downstream. A third cross-section was considered for the velocity measurements, along the cavities centerline (transect E-F, figure 2), with 17 vertical profiles within the street and 37 vertical profiles in each cavity.

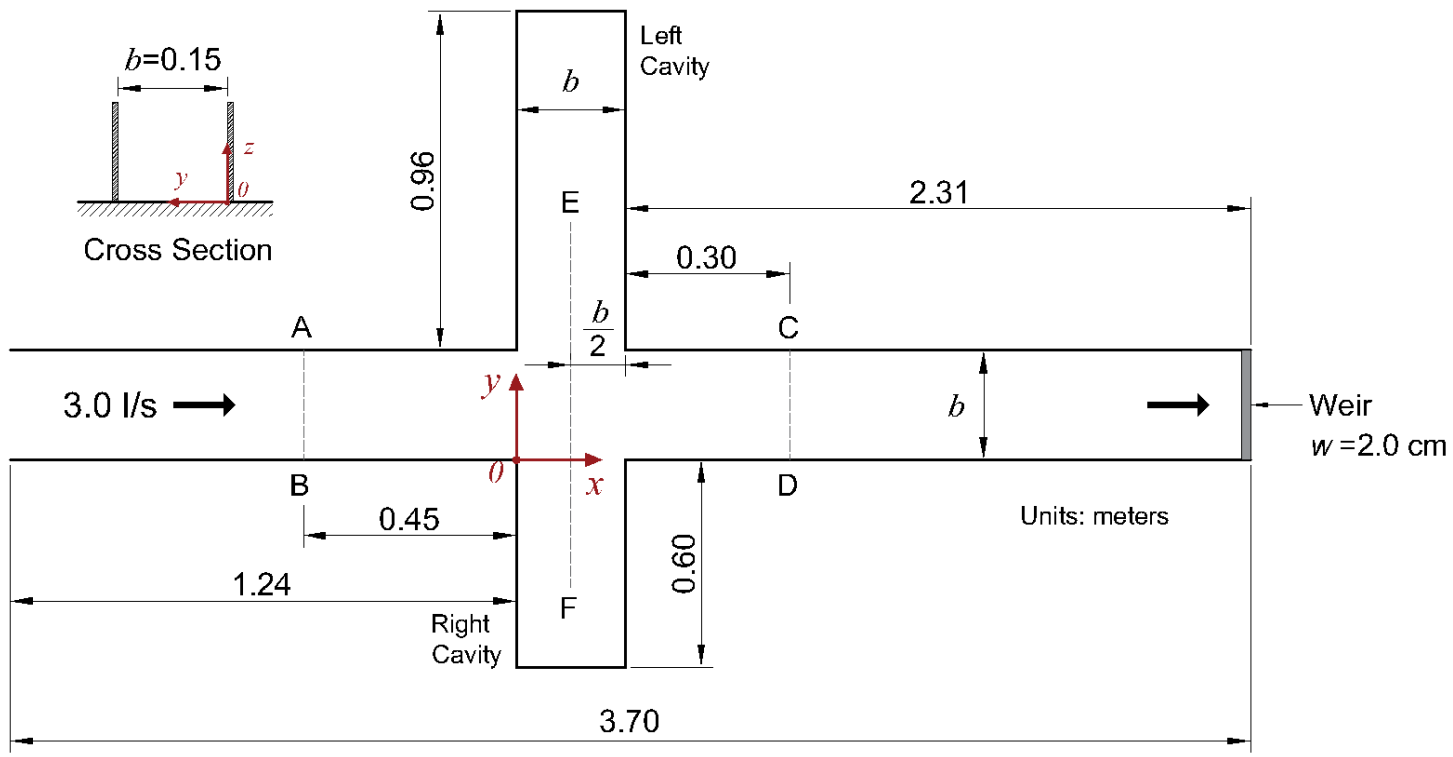


Figure 2. First configuration: a straight street flanked by two lateral cavities. The cavities have the same rectangular cross-section as the street.

\subsection{Straight street flanked by a one-side opening}

The second configuration comprises two parallel incoming streets $(0.12 \%$ longitudinal slope) with a width $b$ $=0.15 \mathrm{~m}$ connected by a third transverse street $\left(90^{\circ}\right.$ angle), with no vertical step (figure 3 ). The inlet discharges in both parallel streets are $1 \mathrm{l} / \mathrm{s}$ and $3 \mathrm{l} / \mathrm{s}$ respectively. The connections have the same cross-section as the streets and are located at the same $x$-position as the cavities. The experiments are performed under steady flow conditions and subcritical regime. As the outlet flow has bifurcated between the side opening $Q_{\text {out } 1}$, and the downstream street reach $Q_{\text {outz, }}$, to keep the flow depth in the downstream branch the same as the previous configuration, the height of the weir in the main street is adjusted to $w=2.4 \mathrm{~cm}$.

The velocity measurements are taken in two cross sections along the main street (transects $\mathrm{G}-\mathrm{H}, \mathrm{I}-\mathrm{J}$, figure 3 ); the first one is located $15 \mathrm{~cm}$ upstream of the opening and the second one $15 \mathrm{~cm}$ downstream. A third transverse section located $15 \mathrm{~cm}$ downstream of the beginning of the branch that connects the parallel streets is also studied (transect K-L, figure 3).

3.70

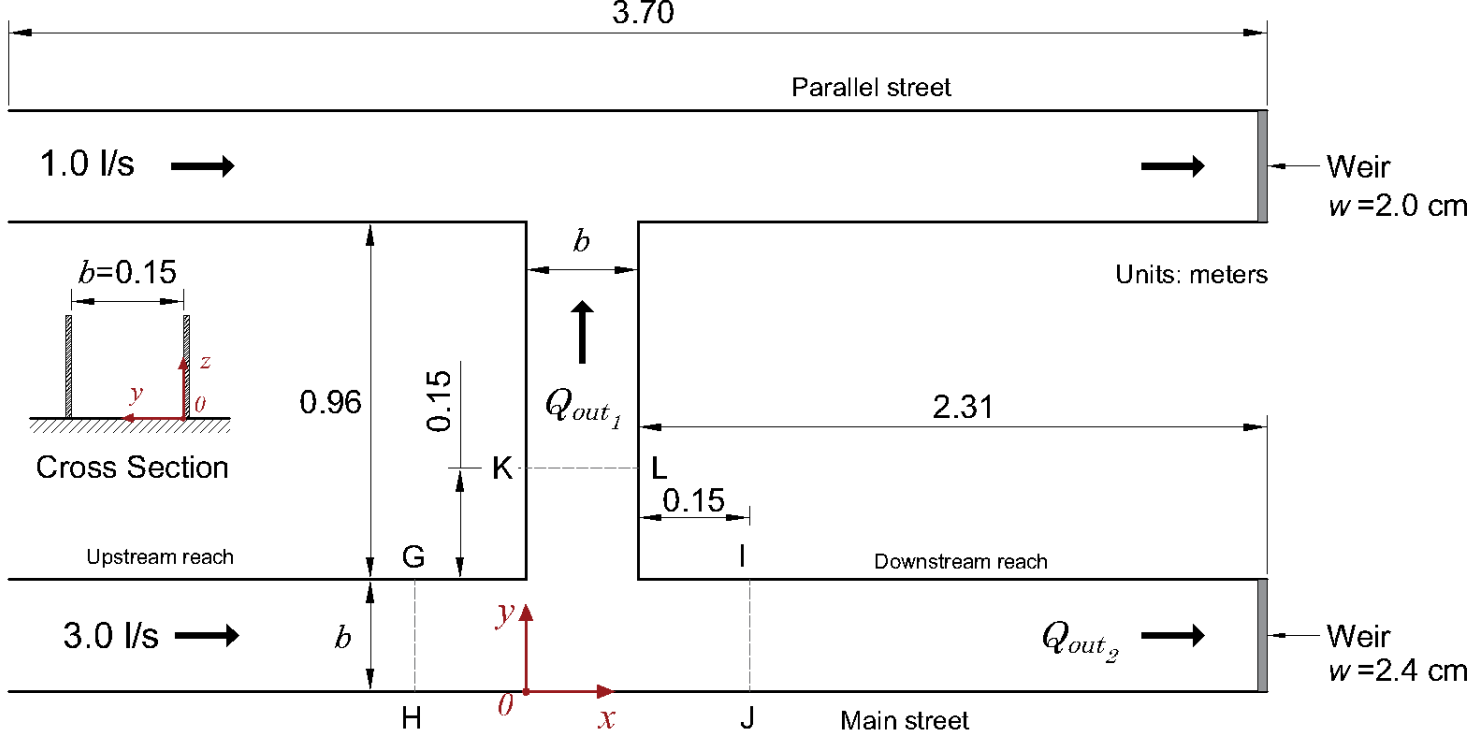

Figure 3. Second configuration: a main straight street flanked by a one-side opening. The opening is of the same width as the main street and it remains so until its confluence with another street parallel to the main street.

The flows in these two configurations will be compared to a reference flow, i.e., a quasi-uniform and subcritical flow in the main street without lateral cavities or one-side opening, of same discharge and downstream flow depth (see the hydraulic parameters in Table 1).

Table 1. Hydraulic parameters of the quasi-uniform and subcritical flow (reference flow).

\begin{tabular}{cccccccc}
\hline$Q(\mathrm{l} / \mathrm{s})$ & $\mathrm{S}_{0}$ & $w(\mathrm{~cm})$ & $b(\mathrm{~cm})$ & $<d>_{x y}(\mathrm{~cm})$ & $U_{b}(\mathrm{~cm} / \mathrm{s})$ & $\mathbf{R}$ & $\mathbf{F}$ \\
\hline 3.00 & 0.0012 & 2.00 & 15.00 & 5.51 & 36.30 & 46100 & 0.49 \\
\hline
\end{tabular}

where $\langle d\rangle_{x y}$ is the averaged flow depth in the horizontal plane, $U_{b}$ is the bulk velocity, $\mathbf{R}$ is the Reynolds number and $\mathbf{F}$ the Froude number.

\section{STREET FLANKED BY TWO LATERAL CAVITIES}

The results show that the lateral cavities cause an increase in flow depth in the upstream reach of the street, compared to the reference flow configuration (figure 4). Despite this flow depth increase, the flow velocity in the street upstream of cavities does not show a substantial change in comparison with the reference flow, as shown in figure 5 . The A-B cross-sections show a roughly symmetrical time-averaged velocity distribution, with very similar velocity ranges in both cases. 


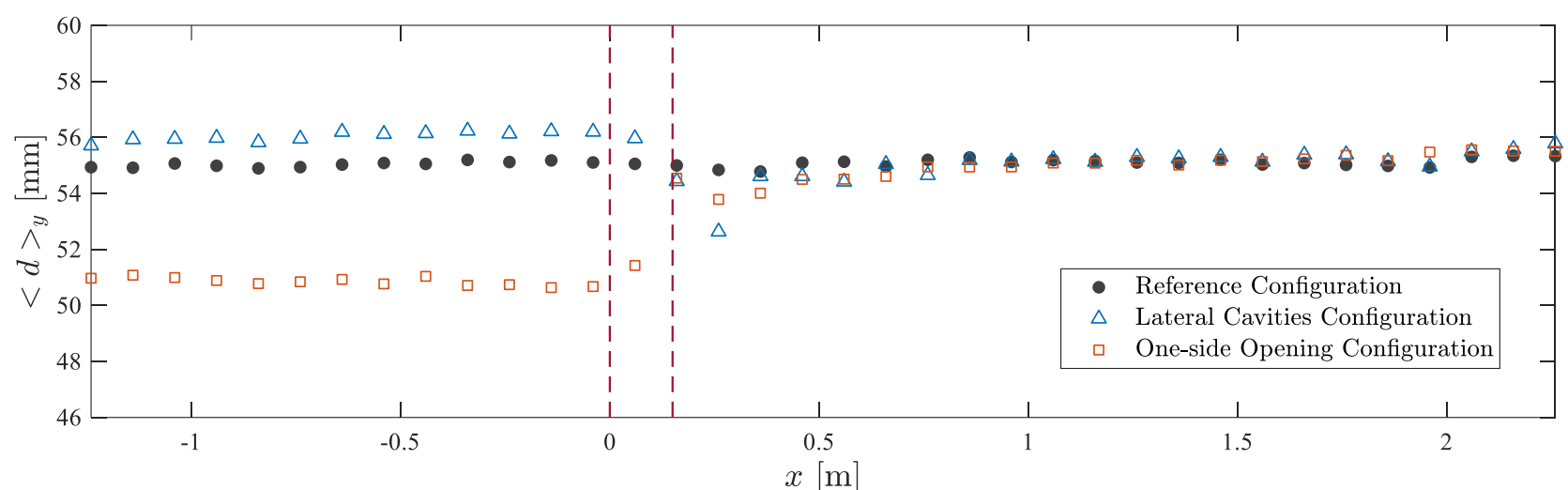

Figure 4. Flow depth laterally averaged, $\langle d\rangle_{y}$, as a function of the longitudinal position $x$ in the main street for the configurations with cavities (figure 2) and one-side opening (figure 3), and for the quasi-uniform and subcritical flow without cavities and opening (reference configuration). The dashed vertical lines indicate the initial and final position of the cavities and opening.

For the street reach downstream of cavities, from the beginning there is a sudden decrease in flow depth, and then rapidly regains the same flow depth as the reference configuration (approximately at $x=2 \mathrm{~m}$, which is $0.6 \mathrm{~m}$ away from the cavities, i.e., 4 times the street width) and remains so until the outlet. This decrease in flow depth causes a local increase in $u / U_{b}$ along the centerline which can be seen in cross section C-D of figure 5 when compared to the reference flow. Although the velocity distribution seems symmetrical, it is possible to observe with the iso-contours of $u / U_{b}$ a slight shift to the left side, which does not appear in the reference configuration. This shift may be due to the different lengths of the two cavities.
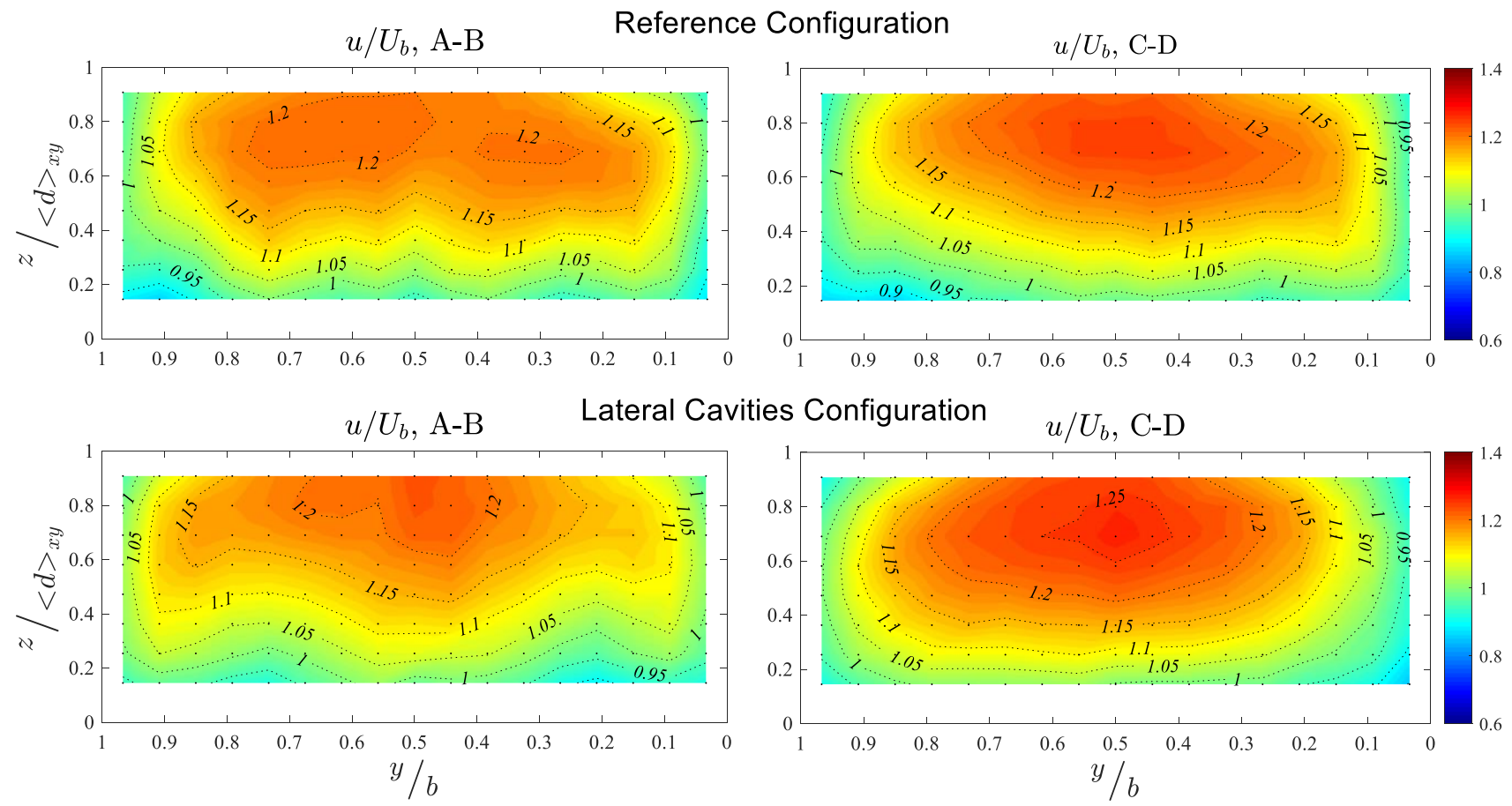

Figure 5. Cross-sectional distribution of dimensionless time-averaged streamwise velocity $u$, in the different transects ( $A-B$ and $C-D$, see figure 2 ) for the reference configuration and the lateral cavities configuration.

Complex flow-features can be observed inside the cavities, such as quasi-periodic vortices produced at the interface between the main flow and the cavity (Mignot et al., 2016). It has been observed that the size of the recirculation zones is the same on both sides, approximately 1.7 times the cavity width (twice the distance from the recirculation core to the mixing layer), as shown in figure 6.

The difference in the streamwise velocity between the street and the cavities can be seen in the upper and lower plot of figure 6 , and it can also be observed that this velocity gradient formed at the cavity-channel interface, known as the mixing layer, is a slight shift to the left bank $(y / b=1)$. In the lower plot of figure 6 that 
shows the transverse gradient of the streamwise velocity, this can be clearly observed, the left mixing layer (corresponding to the longer cavity) is inside the cavity and the right mixing layer is inside the street.
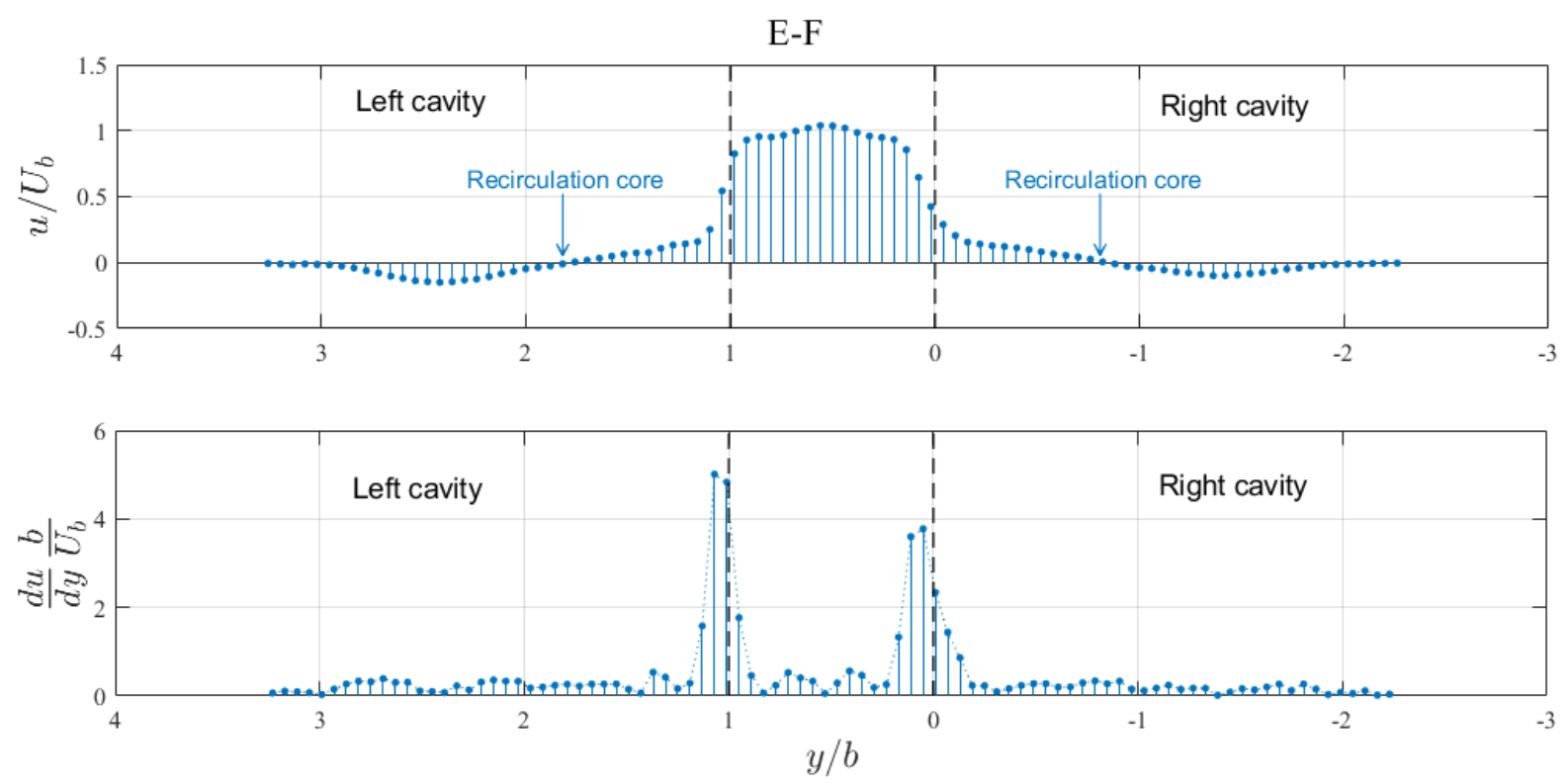

Figure 6. (Top) Transverse distribution of dimensionless time-averaged streamwise velocity $u / U_{b}$; (Bottom) transverse gradient of time-averaged streamwise velocity $d u / d y$ in the transect I-J, normalized by $b / U_{b}$. The black dashed lines indicate the interfaces between main street and cavities.

\section{STRAIGHT STREET FLANKED BY A ONE-SIDE OPENING}

In this second flow configuration, the data exhibit a decrease in flow depth (and subsequently an increase in velocity) in the upstream reach of the main street (approximately $9 \%$ ), compared to the reference configuration (figure 4). The maximum streamwise velocity is clearly shifted to the left side in both sections (i.e., towards the opening), upstream and downstream of the opening location, as shown in figure 7 . In the reference flow, the velocity found in this left zone $(y / b=0.8$, figure 5$)$ was $40 \mathrm{~cm} / \mathrm{s}\left(u / U_{b}=1.1\right)$, while in this configuration it was 50 $\mathrm{cm} / \mathrm{s}\left(u / U_{b}=1.38\right)$, which represents a strong increase of $25 \%$.

One-side Opening Configuration
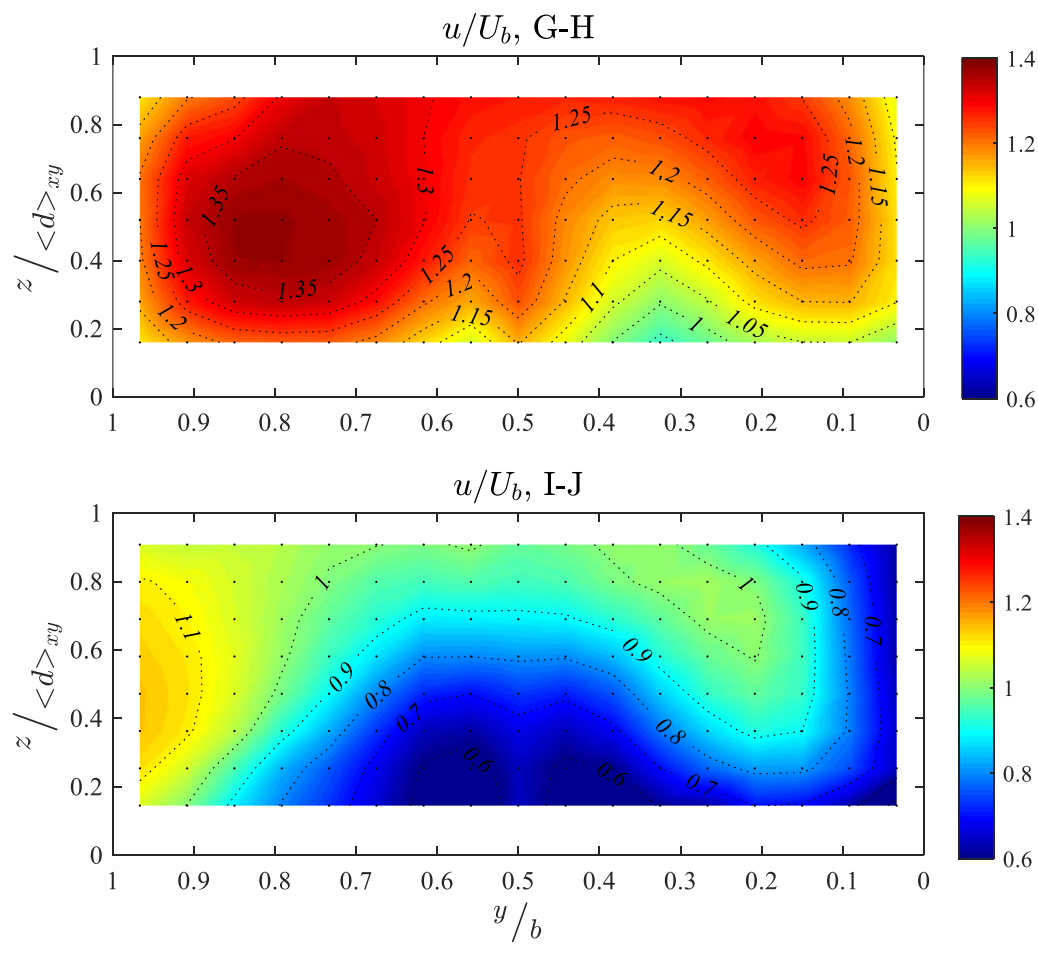
Figure 7. Cross-sectional distribution of dimensionless time-averaged streamwise velocity $u$, in the transects $\mathrm{G}-\mathrm{H}$ and $\mathrm{I}-\mathrm{J}$ for the one-side opening configuration (figure 3).

The distribution of the outflow discharge is $22 \%$ and $78 \%$ of the inflow discharge for $Q_{\text {out } 1}$ and $Q_{\text {out } 2}$ respectively. The flow depth in the downstream reach on the main street remains similar to the reference configuration (figure 4), and with the decrease of the discharge in this zone also the flow velocity significantly decreases in the transect I-J of figure 7.

Table 2. Flow rate distribution in the bifurcation between the main street and the transverse branch (figure 3 )

\begin{tabular}{cc}
\hline Qout $1(1 / \mathrm{s})$ & 0.65 \\
\hline $\mathrm{Q}_{\text {out2 }}(1 / \mathrm{s})$ & 2.35 \\
\hline
\end{tabular}

Figure 8 shows the velocity distribution across the transverse street (transect K-L) connecting the two parallel streets. The velocity decreases substantially from the right side to left side, reaching negative velocities in almost all the left part that indicate the presence of a recirculation area. Although mean velocity is much lower than in the main street, the peak velocity on the right side is nearly as high as in the main street.

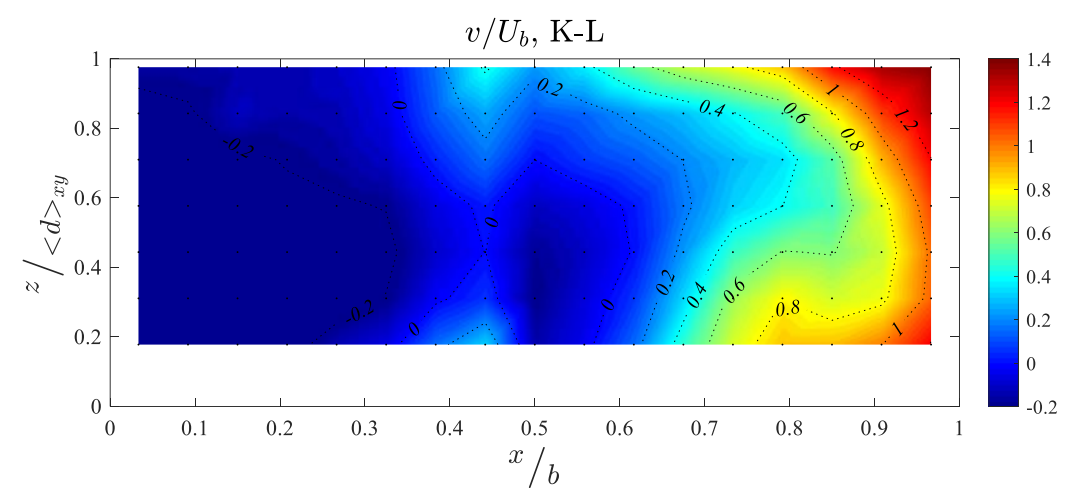

Figure 8. Cross-sectional distribution of dimensionless time-averaged velocity $v$, in the transect K-L for the oneside opening configuration (figure 3).

\section{CONFIGURATION IN PROGRESS}

In addition to the configurations already mentioned, more tests are being performed on another configuration which has the same parallel streets as the second configuration, two transverse streets, and in the middle a pervious block (figure 9). All streets are $0.15 \mathrm{~m}$ wide and the block dimensions are $0.96 \mathrm{~m}$ wide and $1.56 \mathrm{~m}$ long. 


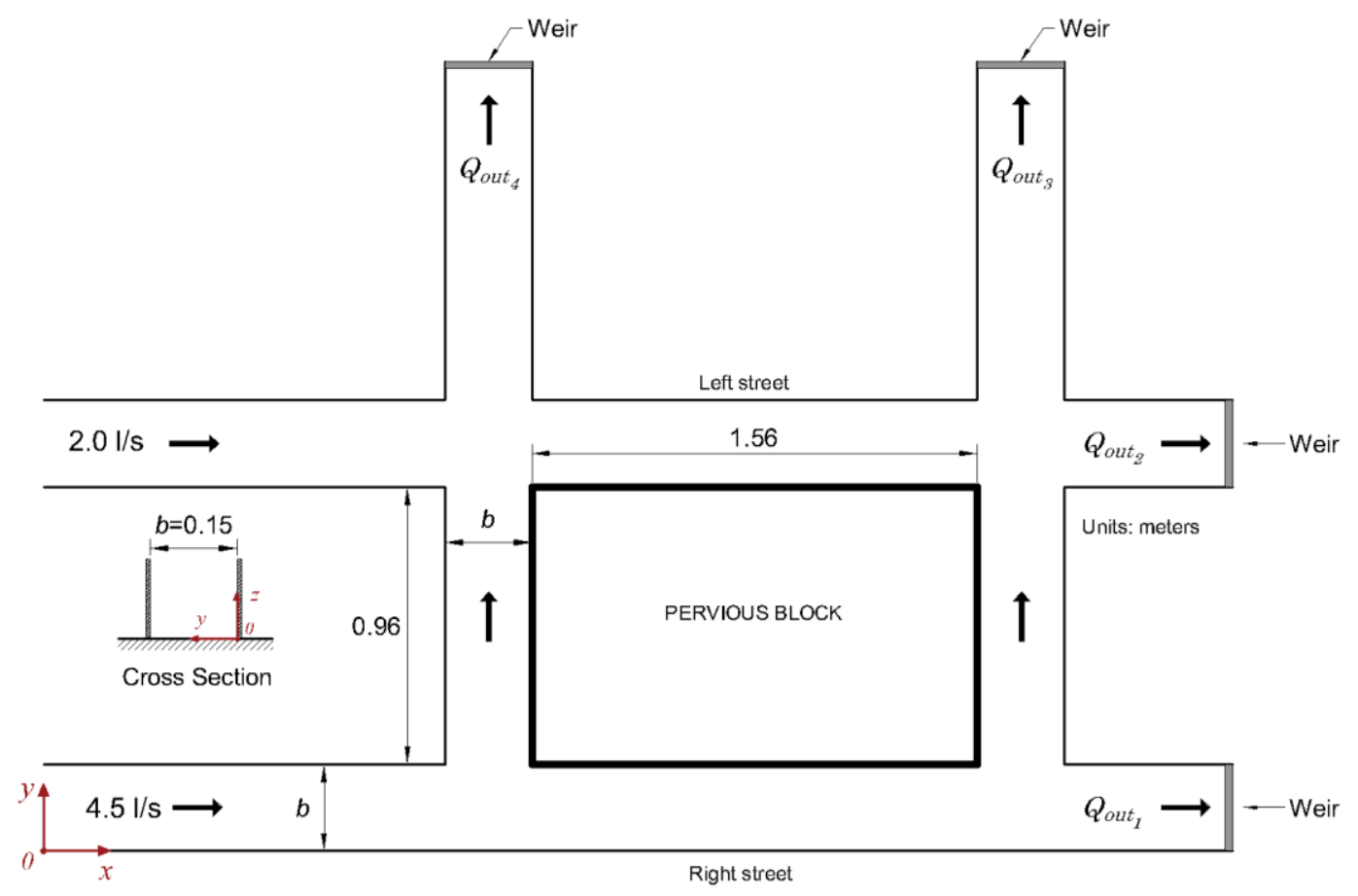

Figure 9. Configuration in progress: Pervious square block surrounded by 4 streets $15 \mathrm{~cm}$ wide.

The inflow discharge in the right street is of $4.5 \mathrm{l} / \mathrm{s}$, and in the left street $2 \mathrm{l} / \mathrm{s}$, the bottom slope is $0.12 \%$. The experiments are carried out under steady flow conditions and subcritical regime. To ensure the subcritical regime, in each outlet a height-adjustable weir is located.

Flow depth measurements will be carried out in the streets and inside the block, water column velocities will be measured with the ADV, and flow surface velocities will be obtained in the entire area using the LSPIV method. The measurements will be performed for various porosity values (number of openings) in the block and they will be compared with a configuration where the block is impervious. For all tests the upstream and downstream boundary conditions will remain the same.

\section{CONCLUSIONS}

The tests carried out with the experimental model MURI provided information on the impact of the exchange of flows between buildings and streets. Although the configurations chosen are simple, it was possible to observe more clearly the impact that these flow exchanges have locally on the flow pattern, mainly changes in flow velocity in certain areas, and the presence of recirculation zones.

In comparison with the reference flow (quasi-uniform and subcritical flow), the first configuration (cavities) showed some slight differences in flow depth in the street, mainly in the upstream reach and immediately downstream of the cavities location, where there is a sudden decrease. The flow velocity also had a slight increase mainly in the downstream reach; however the most relevant in this configuration is the presence of recirculation zones in both cavities.

In the second configuration (with a one-side opening) the modifications of the velocity and the flow depth were more noticeable, decreasing the flow depth in the upstream reach, as well as significantly increasing the flow velocity and shifting the maximum magnitude to the left side.

Therefore, it is very clear that these lateral exchanges with the buildings have an impact on the flow in the streets. For this reason it is really recommended to carry out detailed flood studies, taking into account the effects that buildings have at the local level in certain areas if it is required to estimate flood hazard adequately.

Finally, the results observed have encouraged us to investigate more complex configurations, and it is expected to obtain more detailed information on the effects that the lateral inflows or/and outflows have on the flow depths and velocities in a flooded streets, but also inside the pervious block.

\section{NOTATION}

$$
\begin{aligned}
& b=\text { street width } \\
& d=\text { flow depth } \\
& \mathbf{F}=\text { Froude number }
\end{aligned}
$$


$Q=$ discharge

$Q_{\text {in }}=$ inlet discharge

$Q_{\text {out }}=$ outlet discharge

$\mathbf{R}=$ Reynolds number

$S_{0}=$ street slope in the $x$-axis direction

$u=$ time-averaged velocity in the $x$-axis direction

$U_{b}=$ bulk velocity $(=Q / b d)$

$v=$ time-averaged velocity in the $y$-axis direction

$w=$ height of weir crest

$x, y, z=$ Cartesian coordinates in longitudinal direction, transverse direction and vertical direction

$\langle\ldots\rangle_{x y}=$ spatial averaging in the horizontal plane

$<\ldots\rangle_{y}=$ spatial averaging along $y$-direction

\section{ACKNOWLEDGEMENTS}

The authors acknowledge the financial support offered by the French National Research Agency (ANR) for the project DEUFI (under grant n ${ }^{\circ} \mathrm{ANR}-18-\mathrm{CE} 01-0020$ ).

\section{REFERENCES}

Finaud-Guyot, P., Garambois, P., Araud, Q., Lawniczak, F., Francois, P., Vazquez, J. and Mosé, R. (2018). Experimental insight for flood flow repartition in urban areas. Urban Water Journal, 15:3, 242-250.

Huang, C.-J., Hsu, M.-H., Teng, W.-H., and Wang, Y.-H. (2014). The impact of building coverage in the metropolitan area on the flow calculation. Water, 6, 2449-2466.

Ishigaki, T., Keiichi, T. and Kazuya, I. (2003). Hydraulic model tests of inundation in urban area with underground space. Theme B: Wastewater and Storm-water Quality Management, XXX IAHR Congress, 487-493.

Mignot, E., Cai, W., Launay, G., Riviere, N. and Escauriaza, C. (2016). Coherent turbulent structures at the mixing-interface of a square open channel lateral cavity. Physics of Fluids 28, 045104.

Mignot, E., Li, X. and Dewals, B. (2018). Experimental modelling of urban flooding: a review. Journal of Hydrology, 568, 334-342.

Smith, G.P., Rahman, P.F. and Wasko, C. (2016). A comprehensive urban floodplain dataset for model benchmarking. International Journal of River Basin Management, 14:3, 345-356.

Soares-Frazão, S. and Zech, Y. (2008). Dam-break flow through an idealised city. Journal of Hydraulic Research, 46:5, 648-658.

Sturm, M., Gems, B., Keller, F., Mazzorana, B., Fuchs, S., Papathoma-Köhle, M., and Aufleger, M. (2018). Experimental analyses of impact forces on buildings exposed to fluvial hazards. Journal of Hydrology, 565, 1-13.

Testa, G., Zuccala, D., Alcrudo, F., Mulet, J., and Soares-Frazão, S. (2007). Flash flood flow experiment in a simplified urban district. Journal of Hydraulic Research, 45:sup1, 37-44.

Tomiczek, T., Prasetyo, A., Mori, N., Yasuda, T., and Kennedy, A., 2016. Physical modelling of tsunami onshore propagation, peak pressures, and shielding effects in an urban building array. Coastal Engineering, 117, 97112.

United Nations (2015). World Urbanization Prospects: The 2014 Revision. Department of Economic and Social Affairs, Population Division, New York

Wahlstrom, M. and Guha-Sapir, D. (2015). The human cost of weather-related disasters 1995-2015. UNISDR, Geneva.

Yoon, K. (2007). Experimental study of flood inundation considering urban characteristics. Urban Flood Disaster Management Research Center, Seoul.

Zhou, Q., Yu, W., Chen, A.S., Jiang, C., and Fu, G. (2016). Experimental assessment of building blockage effects in a simplified urban district. Procedia Engineering. 154, 844-852. 